\title{
COMMENT
}

\section{Time to revisit the use of G-CSF after allogeneic haematopoietic cell transplantation in COVID-19 era?}

\author{
Alexandre E. Malek (iD ${ }^{1}$
}

The use of granulocyte colony-stimulating factor (G-CSF) in patients with haematological malignancies is associated with less febrile neutropenia episodes. But in the presence of COVID-19 infection, the administration of G-CSF is challenging as it may trigger a robust inflammatory reaction resulting in cytokine storm, respiratory failure and severe outcomes.

British Journal of Cancer (2021) 124:1183; https://doi.org/10.1038/s41416-020-01195-8

\section{MAIN}

Although the administration of granulocyte colony-stimulating factor (G-CSF) after haematopoietic cell transplantation (HCT) has been shown to accelerate the recovery of neutrophil count and reduce febrile neutropenia episodes, its use has remained controversial with conflicting benefits on the clinical outcomes and the length of hospitalisation. Additionally, the use of G-CSF after allogeneic HCT is not well established, with heightened risk of graft-versus-host disease. ${ }^{1-3}$ G-CSF is a growth factor that can stimulate the expression of interleukin-1 (IL-1), interleukin-6 (IL-6), tumour necrosis factor (TNF)-a mediators and myeloid cell recovery, leading to a potential exuberant inflammatory response during the immune reconstitution and engraftment after transplantation.

This raises concerns for worrisome prognosis among HCT recipients who are contracting severe acute respiratory syndrome coronavirus 2 following HCT primarily during the pre-engraftment period. Given the rapid spread of novel coronavirus 2019 pandemic (COVID-19), confirmed COVID-19 cases have reached more than $31,000,000$ worldwide with 960,000 deaths. ${ }^{4}$ Therefore, more HCT patients are at greater risk of infections and the immunopathogenesis of COVID-19 implicates a virus-driven organ damage followed by a robust inflammatory reaction involving the overexpression of several proinflammatory mediators such as IL-6, TNF and host G-CSF resulting in a cytokine storm that contributes to further vital organ compromise, multisystem dysfunction syndrome and death. ${ }^{5}$

All in all, concurrent COVID-19 infection in HCT recipients receiving G-CSF therapy can potentially lead to deleterious results and poor clinical outcomes. Further studies and clinical data are timely needed to evaluate the safety and benefits of using G-CSF following HCT during COVID-19 pandemic, as controlling the hyperinflammation response secondary to COVID-19 infection is a cornerstone in the management.

\section{ACKNOWLEDGEMENTS}

Not applicable

\section{AUTHOR CONTRIBUTIONS}

A.E.M. had the initial idea and wrote the initial and revised drafts.

\section{ADDITIONAL INFORMATION}

Ethics approval and consent to participate Not applicable.

Consent to publish Not applicable.

Data availability Not applicable.

Competing interests The author declares no competing interests.

Funding information No funding source was used for the creation of this commentary.

Note This work is published under the standard license to publish agreement. After 12 months the work will become freely available and the license terms will switch to a Creative Commons Attribution 4.0 International (CC BY 4.0).

Publisher's note Springer Nature remains neutral with regard to jurisdictional claims in published maps and institutional affiliations.

\section{REFERENCES}

1. Khoury, H. J., Loberiza, F. R., Ringdén, O., Barrett, A. J., Bolwell, B. J., Cahn, J. Y. et al. Impact of posttransplantation G-CSF on outcomes of allogeneic hematopoietic stem cell transplantation. Blood 107, 1712-1716 (2006).

2. Trivedi, M., Martinez, S., Corringham, S., Medley, K. \& Ball, E. D. Optimal use of GCSF administration after hematopoietic SCT. Vol. 43. Bone Marrow Transplant. 43, 895-908 (2009).

3. Ringdén, O., Labopin, M., Gorin, N. C., le Blanc, K., Rocha, V., Gluckman, E. et al. Treatment with granulocyte colony-stimulating factor after allogeneic bone marrow transplantation for acute leukemia increases the risk of graft-versus-host disease and death: A study from the acute leukemia working party of the European group for blood and marrow transplantation. J. Clin. Oncol. 22, 416-423 (2004).

4. WHO coronavirus disease (COVID-19) dashboard. Geneva: World Health Organization. https://covid19.who.int/ (2020).

5. Shi, Y., Wang, Y., Shao, C., Huang, J., Gan, J., Huang, X. et al. COVID-19 infection: the perspectives on immune responses. Cell Death Differ. 27, 1451-1454 (2020).

\footnotetext{
${ }^{1}$ Department of Infectious Diseases, Infection Control and Employee Health, The University of Texas MD Anderson Cancer Center, 1515 Holcombe Blvd., Houston, TX 77030, USA
} Correspondence: Alexandre E. Malek (alex.e.malek@gmail.com)

Received: 27 September 2020 Revised: 5 November 2020 Accepted: 10 November 2020

Published online: 4 January 2021 